\title{
Investigación en Simulación en Latinoamérica: una buena y una mala noticia
}

\author{
Simulation Research in Latin America: Good News and Bad News
}

\author{
Marcia Corvetto,* Rodrigo Rubio**
}

¿P or cuál empiezo? (días y días pensando). Por la mala. Los países latinoamericanos representan aproximadamente el $2 \%$ de la inversión mundial en investigación y desarroIlo (I+D), muy lejos de Norteamérica (39\%), Europa $(31 \%)$ y Asia $(26 \%){ }^{1}$ En una encuesta realizada recientemente, ningún país de América Latina destina más del $1 \%$ de su Producto Interno Bruto a I+D, a diferencia de países como Estados Unidos, que destina un 2.6\%, y Japón, que destinan un 2.4\%.

Desde la Federación Latinoamérica de Simulación (FLASIC) se ha intentado empujar en contra de esta realidad, realizando trabajos para promover el desarrollo de esta área. Se han generado grupos de trabajo, se han dictado conferencias y talleres en congresos, y más recientemente se ha incluido el tema en las conferencias en línea organizadas por FLASIC. Además, existe un creciente interés entre los docentes en Latinoamérica en desarrollar ideas de investigación a lo largo de los años. Reflejo de esto es el progresivo aumento de trabajos de investigación recibidos en los congresos latinoamericanos de simulación, con 70 trabajos en Brasil 2011, 70 en Costa Rica 2013, 127 en Chile 2015 y finalmente 215 artículos de investigación en Argentina 2017. ${ }^{2-3}$

Llevamos años "haciendo" simulación en salud en Latinoamérica. De hecho, hace 22 años comenzó el movimiento académico latinoamericano. ${ }^{4}$ Ya es tiempo de que nos preguntemos: ¿Cómo lo estamos haciendo? ¿Qué impacto genera el entrenamiento en simulación? La gran importancia de hacernos preguntas de investigación, posteriormente intentar responderlas y finalmente escribir lo que hemos hecho, radica en el hecho de que es la única forma de comunicarnos, de mostrar al otro lo que hice y así el otro puede partir desde el siguiente peldaño. Ésa es la forma a través de la cual podremos crecer académicamente. Adicionalmente, si una persona publica, se da a conocer, sus trabajos son citados y dan origen a nuevos estudios, puede optar a apoyo económico para proyectos, puede elevar el nivel de sus investigaciones y, obviamente, prestigiar a la institución a la que pertenece.

En la actualidad, la investigación en simulación en Latinoamérica está en un estado incipiente. La buena noticia es que tenemos mucho espacio para crear y crecer. Es como correr por la cancha solos, con la pelota en los pies, sin oponentes. Hace algunos años, sí teníamos un protocolo de investigación en simulación, y queríamos publicarlo, debíamos escribirlo en inglés o buscar revistas de áreas clínicas que quisieran publicarlo. Pelear con los revisores para que vieran la importancia de nuestro trabajo, que la mayoría de las veces no media un impacto en los pacientes. Hoy, se cumple un gran anhelo, además del gran espacio que hay para generar ideas nuevas, contamos con esta revista en español para poder publicar las iniciativas de cada uno de ustedes. Esta revista será un punto de unión para los apasionados en simulación.

El objetivo de este proyecto es promover y facilitar la cultura de la investigación, impulsar a los docentes para que sean curiosos, para que se hagan preguntas sobre el impacto del entrenamiento con simulación en nuestros docentes, alumnos y, lo más importante, en nuestros pacientes. Este proyecto pretende hacer crecer a toda la comunidad simuladora de Latinoamérica, queremos apoyar a los investigadores, y 
también a aquellos revisores que conforman el comité editorial, dando feedback de expertos a más novatos. Los futuros proyectos de la revista son lograr tener continuidad con tres números anuales, conformar un comité editorial de excelencia, conseguir tener fondos concursables para investigación y tener indexaciones. Para esto, necesitamos la ayuda de cada uno de ustedes, cada granito de arena suma.

Desde nuestra visión, lograr crecer académicamente en simulación depende de que toda la comunidad simuladora, de que todos los países unan sus experiencias, para así lograr vencer las fuerzas que van en contra de la investigación. Para que de esta forma, desde hoy en adelante, se cumpla este sueño, y tengamos un aumento exponencial del número de artículos en investigación en simulación publicados en los siguientes años.

\section{REFERENCIAS}

1. Investigación en América Latina. Inf Tecnol. 2011; 22: 1.

2. Comunicación personal Dr. Augusto Scalabrini.

3. Comunicación personal Dr. Juan Manuel Fraga.

4. Comunicación personal Dr. Adalberto Amaya.
Correspondencia:

Marcia Corvetto

División Anestesiología

Pontificia Universidad Católica de Chile, Marcoleta Núm. 377, Santiago.

Tel: +562 23543270

\section{Agradecimientos}

Queremos también aprovechar para mencionar que esta revista no es sólo producto del trabajo que nosotros, el comité editorial, el consejo editorial y los autores han realizado; es producto del trabajo de todas las mesas directivas de sociedades de simulación que hemos tenido en Latinoamérica, ya que sin su esfuerzo y motivación no se hubieran dado las condiciones para que hoy publiquemos esta revista científica. 